\title{
QUEIJO MACURURÉ FABRICADO EM JACARÉ DOS HOMENS, AL: CARACTERÍSTICAS FÍSICO-QUÍMICAS, MICROBIOLÓGICAS E DE PRODUÇÃ̃O
}

\section{Macururé cheese manufactured in Jacaré dos Homens, AL: physical- chemical, microbiological and production characteristics}

\author{
Lara Fabian Cordeiro Silva ${ }^{1}$, Shaiane Maria Abreu Pastor da Silval, Filipe de Oliveira \\ Melo $^{l}$, Patrícia Érica Fernandes ${ }^{1}$, Luana Cypriano de Souza ${ }^{1 *}$
}

\section{RESUMO}

O queijo Macururé é produzido há cerca de 100 anos por uma única família, no povoado Caititu, localizado na cidade de Jacaré dos Homens, AL. É fabricado a partir de leite cru, por fermentação natural por meio de bactérias autóctones. Possui formato cilíndrico, textura macia, massa fechada, contendo gordura líquida no seu interior, sabor levemente ácido, lembrando manteiga de garrafa, coloração marrom, casca rígida e sem trincas, e massa cozida. Muito apreciado por seu sabor único e pela riqueza cultural e gastronômica, tal produto possui tecnologia de fabricação empírica e artesanal. Visando impedir a extinção da tecnologia de fabricação deste queijo de origem centenária, este trabalho objetivou descrever, de forma técnica e científica, suas etapas de fabricação e caracterizar os aspectos físico-químicos e microbiológicos desse queijo. Foram analisados teores de gordura no extrato seco (GES), acidez, pH, cinzas, umidade e teor de proteína total. Assim, o queijo Macururé pode ser classificado como semigordo e de média umidade, segundo legislação vigente. Os teores de acidez, extrato seco total e gordura variaram significativamente entre os lotes analisados, indicando falta de padronização na fabricação ou da matériaprima utilizada. As análises microbiológicas demonstraram ausência de Salmonella sp. e contagem de coliformes termotolerantes e Staphylococcus aureus dentro dos padrões estabelecidos pela legislação. Este estudo contribuiu para o processo de caracterização de um queijo tipicamente alagoano, com atributos que agregam valor

1 Instituto Federal de Educação, Ciência e Tecnologia de Alagoas, Campus Batalha, Av. Afrânio Lages, s/n, 57420-000, Batalha, AL, Brasil. E-mail: luanasouzaufv@gmail.com

* Autor para correspondência 
por meio do resgate da história e origem cultural e gastronômica, sendo possível, com o regulamento do "Selo Arte", sua comercialização fora da clandestinidade.

Palavras-chave: queijo artesanal; leite cru; gastronomia alagoana; patrimônio imaterial.

\begin{abstract}
Macururé cheese has been produced for about 100 years by a single family, in Caititu village, located in the city of Jacaré dos Homens, AL. It is made from raw milk, by natural fermentation using indigenous bacteria. It has a cylindrical shape, soft texture, closed dough, containing liquid fat inside, slightly acidic flavor, reminiscent of bottled butter, brown color, rigid and without cracks, and cooked pasta. Much appreciated for its unique flavor and cultural and gastronomic richness, this product has empirical and artisanal manufacturing technology. In order to avoid the extinction of the manufacturing technology of this cheese of centenary origin, this work aimed to describe technically and scientifically its manufacturing steps and to characterize the physical-chemical and microbiological aspects of this cheese. The fat content in the dry matter (FDM), acidity, $\mathrm{pH}$, ash, moisture, and total protein content were analyzed. Thus, Macururé cheese can be classified as semi-fat and of medium humidity, according to current legislation. The levels of acidity, total dry extract and fat varied significantly between the batches analyzed, indicating a lack of standardization in manufacturing or in the raw material used. Microbiological analyzes showed the absence of Salmonella sp. and the counting of thermotolerant coliforms and Staphylococcus aureus within the standards established by legislation. This study contributed to the characterization process of a cheese typically from Alagoas, with attributes that add value through the rescue of history, cultural and gastronomic origin, being it possible, with the regulation of "Selo Arte", to sell it outside the clandestine market.
\end{abstract}

Keywords: artisanal cheese; raw milk; Alagoas' gastronomy; intangible heritage.

\section{INTRODUÇÃO}

O queijo Macururé é produzido há cerca de 100 anos por uma única família, atualmente dois irmãos, no povoado Caititu, localizado na cidade de Jacaré dos Homens, AL. Trata-se de um queijo de formato cilíndrico, com peso variando entre $0,5 \mathrm{~kg}$ a $1 \mathrm{~kg}$, textura macia a semidura, massa fechada, contendo gordura líquida no seu interior, sabor levemente ácido, lembrando manteiga de garrafa, coloração caramelo, casca rígida e oleosa, massa cozida e sem trinca. Apresenta elevada resistência quanto a conservação, devido ao baixo conteúdo de água e principalmente ao longo período de exposição a elevadas temperaturas de cocção da massa (entre $80^{\circ} \mathrm{C}$ a $100^{\circ} \mathrm{C}$ por cerca de $6 \mathrm{~h}$ ).

Possui semelhanças sensoriais e físicoquímicas com o requeijão do Sertão e Queijo de Manteiga, este último sendo definido, segundo seu Regulamento Técnico de Identidade e Qualidade (RTIQ) como produto obtido mediante coagulação do 
leite com emprego de ácidos orgânicos de grau alimentício, cuja massa é submetida à dessoragem, lavagem e fusão, com acréscimo exclusivamente de manteiga de garrafa, manteiga da terra ou manteiga do Sertão (BRASIL, 2001).

Em todo Brasil se percebe grande demanda e apreciação pelo consumo de queijos artesanais, seja por serem considerados mais naturais e saborosos ou ainda por agregarem valor por meio da cultura gastronômica e história que carregam em si (PINTO et al., 2011). Além disso, segundo Beresford et al. (2001), os queijos artesanais possuem propriedades sensoriais típicas, com sabor e aromas associados com o leite, a raça e nutrição do animal, o saber fazer próprio de cada queijeiro e a microbiota autóctone responsável pela fermentação e maturação, fornecendo um queijo próprio da região produtora. Vale ressaltar ainda que sua produção é uma das principais fontes de renda para pequenos produtores que os comercializam diretamente com o consumidor ou por meio de atravessadores (ZAFFARI et al., 2007).

O processo de fabricação artesanal do queijo Macururé é totalmente empírico e se mantém o mesmo há três gerações. Assim como ocorre para o Queijo de Manteiga de diversas regiões do Norte e Nordeste, a fabricação do queijo Macururé utiliza leite cru em sua formulação. Segundo Oliveira (1984), a elevada temperatura envolvida no processo de cozimento da massa (cerca de $85^{\circ} \mathrm{C}$ por $15 \mathrm{~min}$ ), durante a fabricação dessa variedade de queijo, dispensa o tratamento térmico prévio da matéria-prima, sob o ponto de vista higiênico-sanitário.

A realização deste trabalho teve como objetivo descrever o processo de fabricação e caracterizar os aspectos físico-químicos e microbiológicos de um queijo artesanal de fabricação centenária, preservando a cultura gastronômica regional e evitando a extinção do processo tecnológico de fabricação.

\section{MATERIAL E MÉTODOS}

\section{Descrição do processo de fabricação do queijo Macururé}

Foram realizadas quatro visitas técnicas entre os meses de agosto e novembro de 2018, onde todas as etapas de fabricação foram acompanhadas e descritas minuciosamente por meio de observação direta, registros audiovisuais e diálogo com o produtor ao longo da fabricação. Também foi realizado o acompanhamento da acidez (\% ácido lático) da massa desde sua obtenção até o processo final de enformagem (por titulação direta com $\mathrm{NaOH} 0,1 \mathrm{~mol} / \mathrm{L})$. Outro parâmetro acompanhado durante todo processo foi a temperatura de escaldagem/lavagem e cocção da massa.

\section{Coleta e transporte das amostras}

Foram realizadas quatro visitas técnicas exploratórias e, a cada visita, foi coletada uma amostra de queijo do lote referente àquele dia de fabricação. A cada coleta, a amostra foi transportada para o Instituto Federal de Alagoas (IFAL), Campus Batalha, em caixa térmica com bolsas de gelo a $4^{\circ} \mathrm{C}$ $\left( \pm 1^{\circ} \mathrm{C}\right)$ e imediatamente acondicionada sob refrigeração para análises no dia posterior.

\section{Análises físico-químicas}

As análises físico-químicas foram realizadas no Laboratório de Físico-Química do IFAL, Campus Batalha. Todas as análises foram realizadas em triplicata e seguiram as metodologias propostas no manual de análises físico-químicas do Instituto Adolfo Lutz (ZENEBON et al., 2008). As amostras foram submetidas às seguintes determinações: teor de umidade, em estufa a $105^{\circ} \mathrm{C}$; cinzas, obtida por meio de mufla a $550^{\circ} \mathrm{C}$; gordura total e no extrato seco total, segundo o método de 
Gerber; acidez por titulação direta com $\mathrm{NaOH}$ $0,1 \mathrm{~mol} / \mathrm{L}$, expressa em porcentagem de ácido lático por grama de amostra; $\mathrm{pH}$, utilizando potenciômetro portátil devidamente aferido; e proteína total, pelo método semi-micro Kjeldahl. O teor de proteína total (PT) foi determinado de modo indireto, multiplicandose a \% de nitrogênio total encontrado (NT) pelo fator de conversão (F) da relação nitrogênio/ proteína, de acordo com a fórmula: $\mathrm{PT}=\mathrm{NT} \times \mathrm{F}$. No caso de produtos lácteos, o valor de F é 6,38; segundo as normas da Association of Official Analytical Chemists (HORWITZ, 2000).

\section{Análises microbiológicas}

As análises microbiológicas dos quatro lotes avaliados ocorreram no Laboratório de Análises Microbiológicas de Alimentos (LABAMA) do IFAL, Campus Batalha. As amostras foram avaliadas quanto à contagem de coliformes a $35^{\circ} \mathrm{C}$ (totais) e a $45^{\circ} \mathrm{C}$ (termotolerantes), Staphylococcus aureus e presença de Salmonella sp.

De cada amostra, foi retirado, de diferentes partes do queijo, um total de $25 \mathrm{~g}$ e adicionado assepticamente em sacos plásticos apropriados (previamente esterilizados em autoclave a $121^{\circ} \mathrm{C}$ por $15 \mathrm{~min}$ ) e homogeneizadas manualmente em $225 \mathrm{~mL}$ de solução salina peptonada (SSP) $0,1 \%$ a fim de obter-se a diluição inicial $\left(10^{-1}\right)$. Em seguida, 1,0 mL desta diluição foi colocado num tubo contendo $9 \mathrm{~mL}$ de SSP $0,1 \%$, obtendo-se a diluição $10^{-2}$, e tal procedimento foi repetido para obtenção da diluição $10^{-3}$.

Para análise de coliformes totais e termotolerantes utilizou-se o método do Número Mais Provável (NMP). Para determinação do NMP de coliformes totais, de cada diluição $\left(10^{-1}\right.$ a $\left.10^{-3}\right)$ do alimento em estudo, foram tomadas três porções de $1,0 \mathrm{~mL}$ cada e inoculadas, respectivamente, em três tubos contendo $10 \mathrm{~mL}$ de Caldo Lauril Sulfato
Triptose (LST, KASVI) contendo um tubo de Durham invertido, obtendo-se três séries de três tubos, os quais foram incubados em estufa a $35^{\circ} \mathrm{C}\left( \pm 1^{\circ} \mathrm{C}\right)$, por 24 a $48 \mathrm{~h}$. Os subcultivos positivos foram semeados em tubos contendo $8 \mathrm{~mL}$ de Caldo Verde Brilhante Bile $\%$ (VB, KASVI) com tubo de Durham invertido, incubando-os a $35^{\circ} \mathrm{C}$, durante um período de 24 a $48 \mathrm{~h}$. A prova foi considerada positiva somente quando se verificava turvação do meio e produção de gás nos tubos de Durham, dentro de um período de incubação máximo de 48 h. A determinação quantitativa foi realizada de acordo com a técnica do NMP, recomendada pela American Public Health Association (APHA) (BLODGETT, 2010). Uma alçada de cada cultura foi tomada dos tubos positivos de LST e transferida para tubos de Caldo Escherichia coli (EC, KASVI), contendo tubos de Durham invertidos, e incubados a $45^{\circ} \mathrm{C}$, em banho-maria, para determinação de coliformes termotolerantes. Após a incubação por 24 a $48 \mathrm{~h}$ foi realizada a leitura, e os tubos que apresentavam turvação do meio e produção de gás foram considerados positivos para bactérias do grupo coliforme termotolerante. Para cada diluição, o número de tubos positivos foi anotado e quantificado utilizando-se da tabela de NMP determinando, assim, o número mais provável de coliformes totais e termotolerantes por grama de queijo analisado.

A quantificação de $S$. aureus foi realizada utilizando o método de plaqueamento Spread plate em Agar Baird Parker (BP, KASVI), suplementado com emulsão de gema de ovo com telurito, segundo metodologia proposta pela APHA (BENNETT; HAIT, 2011). A análise foi realizada em duplicata, depositando-se $0,1 \mathrm{~mL}$ de cada diluição sobre a superfície do ágar e, com o auxílio de uma alça de Drigalsky flambada, espalhou-se o inóculo por toda a superfície do meio até a completa absorção. As placas foram incubadas a $35^{\circ} \mathrm{C}\left( \pm 1^{\circ} \mathrm{C}\right)$ e não sendo observado 
crescimento de colônias típicas após 24 a 48 $\mathrm{h}$ a análise foi finalizada.

Para verificação de presença de Salmonella sp. utilizou-se metodologia proposta pela APHA (DOWNES; ITO, 2001) com adaptações. Inicialmente, foram pesados $25 \mathrm{~g}$ de diferentes partes do queijo Macururé em sacos plásticos apropriados e previamente esterilizados em autoclave $\left(121^{\circ} \mathrm{C}\right.$ por $\left.15 \mathrm{~min}\right)$ e homogeneizados manualmente em $225 \mathrm{~mL}$ de caldo lactosado (CL). A mistura foi mantida em incubação a $35^{\circ} \mathrm{C}$ por $24 \mathrm{~h}$. Após este período, 1,0 $\mathrm{mL}$ de cada cultivo foi transferido para tubos de ensaio contendo $10 \mathrm{~mL}$ de caldo selenito cistina (SC) e tubos contendo $10 \mathrm{~mL}$ de caldo tetrationato (TT), posteriormente incubados a $35^{\circ} \mathrm{C}$ por $24 \mathrm{~h}$. Após o período de incubação, foram realizadas semeaduras em placas de Petri contendo ágar Salmonella Shigella (SS) e incubadas em estufa $35^{\circ} \mathrm{C}$ por $48 \mathrm{~h}$. Como não houve crescimento de colônias suspeitas, a análise foi finalizada.

\section{Delineamento experimental e análise estatística dos dados}

As amostras foram selecionadas por meio de Delineamento Inteiramente Casualizado (DIC) e analisadas em triplicata. Os resultados dos parâmetros físico-químicos foram tabulados e submetidos à análise de variância (ANOVA) e as médias comparadas pelo teste de Tukey a 5\% de probabilidade, para avaliar a variabilidade entre os lotes. Foi utilizado o software SISVAR versão 5.6. (FERREIRA, 2011).

\section{RESULTADOS E DISCUSSÃO}

\section{Descrição do processo de fabricação do queijo Macururé}

A fabricação do queijo Macururé ocorre nas diferentes etapas descritas a seguir:

1. O leite utilizado na fabricação dos queijos é adquirido de produtores locais, do povoado Caititu, no município de Jacaré dos Homens, AL. O mesmo é transportado em latões com capacidade para $10 \mathrm{~L}$ até a fazenda onde o produto é processado.

2. Ao chegar na propriedade onde o queijo é fabricado, o leite é filtrado em tecido de algodão e transferido para um tambor plástico com capacidade de $200 \mathrm{~L}$.

3. Este tambor é coberto com tampa própria. $\mathrm{O}$ mesmo permanece em temperatura ambiente $\left(28 \pm 1^{\circ} \mathrm{C}\right)$ e o processo de coagulação ácida ocorre de forma natural por bactérias autóctones, presentes no leite cru. Segundo o queijeiro, a coagulação ocorre dentro de $36 \mathrm{~h}$, quando se tem a coalhada já formada. O ponto de corte da coalhada é definido visualmente ou utilizando a própria mão.

4. A coalhada obtida é dessorada em saco de nylon (ráfia) e o soro recolhido é destinado a alimentação animal. Após a dessoragem, a massa proteica passa por escaldagem com água a $100^{\circ} \mathrm{C}$ e desintegração manual da massa. Segundo o produtor, tal procedimento é realizado a fim de "lavar a massa". Do ponto de vista tecnológico, tal lavagem é fundamental para reduzir a elevada acidez presente na massa. Segundo o produtor, "se a massa ficar muito ácida no final, o queijo não dá liga e se esfarela todo" (informação verbal $^{2}$ ). Essa redução da acidez está representada na Figura 1, onde observa-se a queda na concentração de ácido lático a cada processo de

2 Transcrição de entrevista semiestruturada com o produtor Vicente no dia 02 de agosto de 2018. 
lavagem, com água e leite.

5. Em seguida, a massa recebe a mesma proporção de leite (em relação ao volume de água previamente adicionada). Neste momento a massa continua sob branda agitação em aquecimento. A mistura da massa é feita com pá de madeira. Após um período de 30 min nestas condições, a massa é escorrida em saco nylon (ráfia). O leite remanescente desta etapa é armazenado para posterior recuperação de creme por desnate natural. O processo de lavar e escorrer a massa se repete por 3 a 5 vezes consecutivas, a depender do ponto final definido pelo olhar e tato do queijeiro.

6. Após a última escaldagem, a massa é novamente adicionada de leite, desintegrada e permanece sob aquecimento (cocção) por um período de aproximadamente $4 \mathrm{~h}$. Após este período, a massa é escorrida e um novo volume de leite é adicionado na panela até alcançar temperatura de $95^{\circ} \mathrm{C}$. Neste momento, a massa retorna para a panela, sofre nova desintegração manual e é acrescida de creme de leite (obtido por desnate natural) e manteiga de garrafa (produzida na hora pelo próprio queijeiro).

7. A mistura de todos esses componentes ocorre de maneira manual com auxílio de pá de madeira por mais 3 h. Ao longo desse período a massa vai ganhando coloração caramelo, provavelmente devido a reação de Maillard e adição de manteiga de garrafa.

8. Após este período de cocção sob contante agitação, a massa é novamente escorrida, volta para a panela e recebe adição de sal. A quantidade de sal adicionada é medida na mão do queijeiro, de forma empírica. A mistura continua sob aquecimento até que a massa obtenha ponto de enformagem. A enformagem acontece em formas feitas a partir de canos de PVC e os queijos são embalados em recipientes plásticos sem rotulagem. Algumas das etapas de fabricação do queijo Macururé estão ilustradas na Figura 2.

É interessante observar que todo o processo de fabricação ocorre de maneira rudimentar, com fogo a lenha, pá de madeira e totalmente manual, sendo necessária diversas adequações relacionadas às Boas Práticas de Fabricação (BPF). O fato do processo de

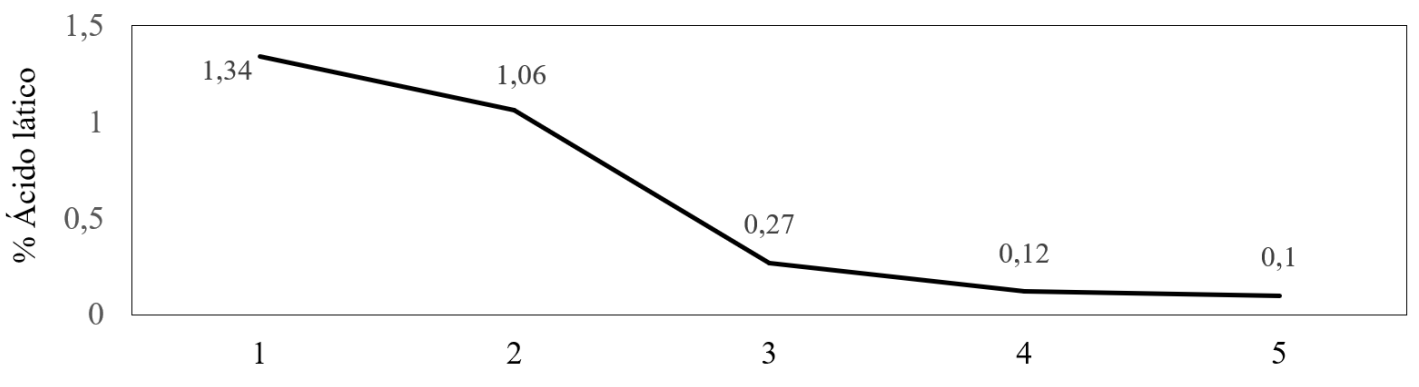

Etapas da fabricação

Figura 1 - Redução da acidez (\% ácido lático) ao longo do processo de lavagem e escaldagem da massa durante a fabricação do queijo Macururé 
fabricação ocorrer em elevadas temperaturas (entre $80^{\circ} \mathrm{C}$ a $100^{\circ} \mathrm{C}$ ) durante cerca de $6 \mathrm{~h}$ contribui para boa conservação do produto.

\section{Caracterização físico-química e rendimento do queijo Macururé}

Os resultados das análises físicoquímicas estão representados na Tabela 1.
É possível verificar que existe diferença significativa para parâmetros de $\mathrm{pH}$, acidez titulável, umidade, EST e GES, quando observamos os valores individuais para cada lote. Os valores de acidez (\% ácido lático) e $\mathrm{pH}$ dos quatro lotes apresentaram diferença estatística pelo teste de Tukey $(\mathrm{p}<0,05)$, sendo que apenas os lotes 3 e 4 não apresentaram diferença significativa para estes parâmetros.
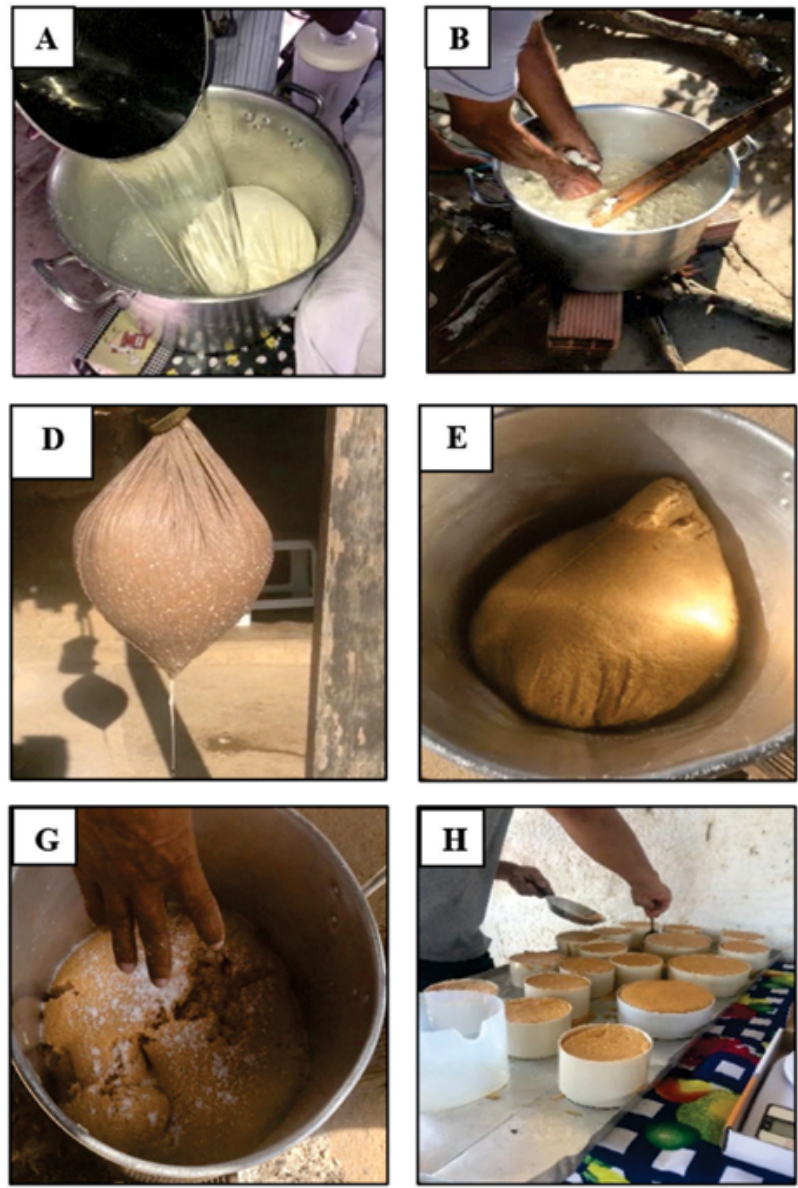
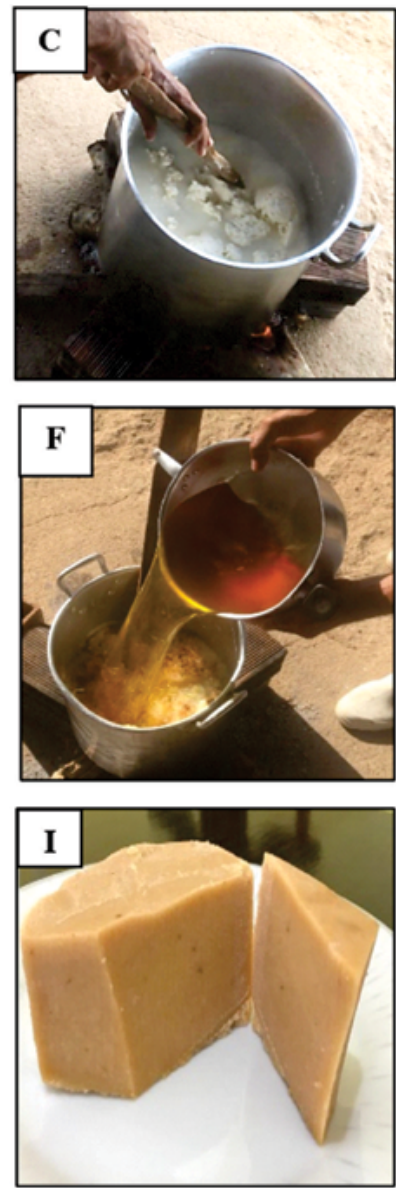

Figura 2 - Escaldagem da massa com água a $100^{\circ} \mathrm{C}(\mathrm{A})$; Desintegração da massa e adição de leite sob aquecimento (B); Massa adicionada de leite sob cocção a $90^{\circ} \mathrm{C}(\mathrm{C})$; Massa sendo escorrida em saco de nylon (ráfia) (D); Massa obtida após aproximadamente 4 horas de cocção (E); Adição de manteiga de garrafa à massa $(\mathrm{F})$; Processo de salga diretamente na massa $(\mathrm{G})$; Enformagem em formas feitas de PVC (H); Queijo Macururé um dia após a fabricação (I) 
Este resultado pode ser explicado devido à falta de padronização no processo de redução da acidez por meio das consecutivas lavagens da massa. A determinação do ponto final da massa é realizada de forma totalmente empírica, pela avaliação da textura e aroma. De acordo com o Sr. Vicente, produtor do queijo Macururé, "a gente sabe que já tá bom de escaldar quando a gente pega os pedaços de massa na mão e eles se juntam sem se desmanchar"3. Nassu et al. (2003), estudando a composição físico-química de Queijos de Manteiga de diferentes produtores artesanais do Rio Grande do Norte, encontrou valores de acidez entre $0,12 \%$ e $1,85 \%$. Aquino (2011), estudando amostras de requeijão do Sertão na Bahia encontrou resultado semelhante, com teor de acidez variando entre $0,27 \%$ e $0,55 \%$ e atribuiu esse comportamento à falta de padronização no número de lavagens da massa.

Os lotes de queijo avaliados neste trabalho apresentaram valores de umidade com média de 43,73\%. Pelos parâmetros estabelecidos na legislação Federal (BRASIL,
1996) o queijo Macururé é considerado de média umidade e seu teor de umidade está de acordo com o proposto para o RTIQ de queijo de Manteiga, que deve apresentar um teor máximo de umidade de $54,9 \% \mathrm{~m} / \mathrm{m}$. Seixas et al. (2014) encontraram valores semelhantes de umidade para queijo do Marajó tipo Manteiga, variando entre $42,73 \%$ a $52,11 \%$.

Os valores de EST das amostras de queijo Macururé estão em concordância com dados da literatura para Queijos de Manteiga e queijos similares (CAVALCANTE; COSTA, 2005; SEIXAS et al., 2014; AQUINO, 2011), porém variam em função das formulações preparadas.

Pelas médias de valores obtidos para gordura no extrato seco, $39,45 \%$, é possível classificar o queijo Macurué como "semi gordo" (queijos que apresentam entre 25\% e $44,9 \%$ de gordura no extrato seco) (BRASIL, 1996). Nassu et al. (2003), encontrou valores semelhantes $(33,20 \%$ e $38,39 \%)$ de GES para Queijos de Manteiga industrializados e artesanais produzidos no Rio Grande do

Tabela 1 - Valores médios e desvio padrão de parâmetros físico-químicos de quatro lotes de Queijo Macururé fabricados entre os meses de agosto e novembro de $2018^{*}$

\begin{tabular}{cccccc}
\hline \multirow{2}{*}{ Parâmetro } & \multicolumn{4}{c}{ Lotes } & \multirow{2}{*}{ Média $\pm \mathbf{D P}^{1}$} \\
\cline { 2 - 5 } & $\mathbf{1}$ & $\mathbf{2}$ & $\mathbf{3}$ & $\mathbf{4}$ & \\
\hline $\mathrm{pH}$ & $5,9^{\mathrm{b}}$ & $6,3^{\mathrm{a}}$ & $5,7^{\mathrm{c}}$ & $5,5^{\mathrm{c}}$ & $5,98 \pm 0,22$ \\
Acidez (\% ácido lático) & $0,35^{\mathrm{b}}$ & $0,18^{\mathrm{c}}$ & $0,44^{\mathrm{a}}$ & $0,41^{\mathrm{a}}$ & $0,35 \pm 0,08$ \\
Umidade (\%) & $45,6^{\mathrm{a}}$ & $44,2^{\mathrm{ab}}$ & $41,9^{\mathrm{b}}$ & $43,2^{\mathrm{a}}$ & $43,73 \pm 1,17$ \\
EST $^{2}(\%)$ & $54,4^{\mathrm{b}}$ & $55,8^{\mathrm{ab}}$ & $58,1^{\mathrm{a}}$ & $56,80^{\mathrm{a}}$ & $56,38 \pm 1,22$ \\
GES $^{3}(\%)$ & $44,1^{\mathrm{b}}$ & $33,45^{\mathrm{c}}$ & $33,32^{\mathrm{c}}$ & $46,95^{\mathrm{a}}$ & $39,45 \pm 6,07$ \\
Proteína (\%) & $25,7^{\mathrm{a}}$ & $24,3^{\mathrm{a}}$ & $24,5^{\mathrm{a}}$ & $23,1^{\mathrm{a}}$ & $24,4 \pm 0,7$ \\
Cinzas (\%) & $1,91^{\mathrm{a}}$ & $1,81^{\mathrm{a}}$ & $2,77^{\mathrm{a}}$ & $2,30^{\mathrm{a}}$ & $2,20 \pm 0,34$ \\
\hline
\end{tabular}

1 Valores seguidos pela mesma letra, na linha, não diferem entre si ao nível de $5 \%$ de significância pelo teste de Tukey. ${ }^{1} \mathrm{DP}=$ desvio padrão; ${ }^{2} \mathrm{EST}=$ extrato seco desengordurado; ${ }^{3} \mathrm{GES}=$ gordura no extrato seco.

3 Transcrição de entrevista semiestruturada com o produtor Vicente no dia 02 de agosto de 2018. 
Norte. Aquino (2011), estudando amostras de Requeijão do Sertão produzidos na Bahia encontrou valor médio de GES igual a 43,34\%. É interessante observar que, com exceção dos lotes 3 e 4, os lotes apresentaram diferenças significativas $(\mathrm{p}<0,05)$ entre si. Tal variação pode ser resultado da quantidade variável de manteiga de garrafa e creme de leite adicionado em cada lote produzido.

Os teores de proteínas dos quatro lotes avaliados não apresentaram diferença significativa entre si ( $\mathrm{p}>0,05)$, resultando em um valor médio de $24,4 \%$, valor semelhante ao encontrado na literatura para queijos de Manteiga e similares (AQUINO, 2011; JAS SEN-ESCUDERO; RODRIGUEZAMÁYA, 1981; NASSU et al., 2003).

O mesmo comportamento ocorreu para o teor de cinzas, não apresentando diferença significativa entre os lotes $(p>0,05)$ e valor médio igual a 2,20\%. Tal valor também está em concordância com dados encontrados na literatura para queijos similares ao queijo Macururé (SEIXAS et al., 2014; SANTOS et al., 2008; NASSU et al., 2003).

\section{Avaliação da qualidade microbiológica}

Os resultados das análises microbiológicas para a avaliação das condições higiênico-sanitárias dos quatro lotes de queijo
Macururé foram comparados com parâmetros estabelecidos com a RDC n⿳10 da Agência Nacional de Vigilância Sanitária (ANVISA) (BRASIL, 2001) e estão apresentados na Tabela 2.

A presença ou a elevada concentração de micro-organismos indicadores nos derivados lácteos pode indicar condições precárias de higiene na produção, nas etapas pós processamento ou ainda, má qualidade da matéria-prima utilizada. No entanto, os resultados obtidos nessa pesquisa demonstram que todas as amostras analisadas apresentaram contagens microbiológicas dentro dos limites da legislação vigente para queijos de média umidade.

É provável que tal resultado esteja relacionado às elevadas temperaturas de fusão e cocção $\left(80^{\circ} \mathrm{C}\right.$ a $\left.90^{\circ} \mathrm{C}\right)$ da massa que permanecem nessa condição ao longo de quase $6 \mathrm{~h}$ de fabricação do queijo.

\section{CONCLUSÕES}

A descrição técnica do processo de fabricação do queijo Macururé é inédita e, por meio dela, é possível verificar que existem etapas e processos únicos e intrínsecos ao saber fazer do queijeiro. Tais características associadas à territorialidade de fabricação, bem como à história familiar e cultural, podem

Tabela 2 - Resultado das análises microbiológicas de quatro lotes de queijo Macururé analisados entre os meses de agosto e novembro de 2018

\begin{tabular}{|c|c|c|c|c|c|}
\hline \multirow{2}{*}{ Micro-organismos } & \multicolumn{4}{|c|}{ Lotes } & \multirow{2}{*}{ Padrão ${ }^{1}$} \\
\hline & 1 & 2 & 3 & 4 & \\
\hline Coliformes a $35^{\circ} \mathrm{C}(\mathrm{NMP} / \mathrm{g})$ & $<3$ & 11 & 27 & $<3$ & $\mathrm{sd}^{2}$ \\
\hline Coliformes a $45^{\circ} \mathrm{C}(\mathrm{NMP} / \mathrm{g})$ & $<3$ & $<3$ & 15 & $<3$ & $<10^{3}(\mathrm{NMP} / \mathrm{g})$ \\
\hline Salmonella spp. em $25 \mathrm{~g}$ & Ausente & Ausente & Ausente & Ausente & Ausência \\
\hline S. aureus (UFC/g) & $<10^{2}$ & $<10^{2}$ & $<10^{2}$ & $<10^{2}$ & $<10^{3}(\mathrm{UFC} / \mathrm{g})$ \\
\hline
\end{tabular}


conferir a este produto grande potencial para obtenção do selo de identificação geográfica (IG) e agregar valor ao produto.

O queijo Macururé não possui RTIQ próprio, mas quando comparado com o queijo de Manteiga, seus aspectos físico-químicos apresentam grande semelhança.

A variabilidade entre os parâmetros físico-químicos dos queijos de diferentes lotes pode ser explicada pela falta de padronização na fabricação, principalmente nos quesitos lavagem da massa, conteúdo de creme e mateiga de garrafa adicionados, além do tempo e temperatura de cozimento. Tais características são típicas da fabricação artesanal. Segundo o produtor, "tem vez que o queijo desanda, que a gente perde a produção toda do dia"4.

A elevada temperatura de fusão e cocção da massa $\left(80^{\circ} \mathrm{C}\right.$ a $\left.90^{\circ} \mathrm{C}\right)$ por quase $6 \mathrm{~h}$ de fabricação resulta em baixas contagens de coliformes totais e termotolerantes, ausência de $S$. aureus e Salmonella sp.

O queijo Macururé é muito requisitado pela população local, encomendado como presente a um vizinho ou familiar e, atualmente, tem ganhado espaço em grandes centros e restaurantes que valorizam a cultura gastronômica regional. Apesar do grande potencial deste produto, é imprescindível que o fabricante consiga se adequar às normas de BPF e aperfeiçoar o processo de fabricação, visando oferecer um produto seguro e dentro da legalidade, porém, sem descaracterizá-lo. Vale ressaltar ainda a importância de se caracterizar e descrever o processo de fabricação destes produtos artesanais, evitando desta forma a extinção da cultura gastronômica local inerente ao saber fazer do queijeiro.

\section{AGRADECIMENTOS}

Os autores agradecem à receptividade e disponibilidade da família "Moisés", em especial ao Sr. Vicente, produtor do queijo Macururé, em transferir seu valioso conhecimento empírico, possibilitando assim o desenvolvimento desta pesquisa e perpetuação de um processo de fabricação centenário de um queijo tipicamente alagoano. Agradecemos a Pró-Reitoria de Pesquisa, PósGraduação e Inovação (PRPPI) do Instituto Federal de Educação, Ciência e Tecnologia de Alagoas (IFAL) pela concessão da bolsa de estudo e ao IFAL Campus Batalha por estimular a pesquisa e inovação em nossos alunos.

\section{REFERÊNCIAS}

AQUINO, A. A. Requeijão do Sertão fabricado na microrregião de Guanambi, Bahia: Características físico-químicas, microbiológicas e de produção. Orientador: Antônio Fernandes de Carvalho. 2011. 183 f. Tese (Doutorado em Ciência dos Alimentos) - Departamento de Tecnologia de Alimentos, Universidade Federal de Viçosa, Viçosa, 2011.

BENNETT, R. W.; HAIT, J. M. Staphylococcal enterotoxins: Micro-slide double diffusion and ELISA-based methods. In: FOOD AND DRUG ADMINISTRATION (ed.). Bacteriological Analytical Manual. Silver Spring: FDA, 2011. cap 13A.

BERESFORD, T. P. et al. Recent advances in cheese microbiology. International Dairy Journal, v. 11, n. 4-7, p. 259-274, 2001. DOI: 10.1016/S0958-6946(01)00056-5

BLODGETT, R. Appendix 2 - Most probable number from serial dilutions. In: FOOD AND DRUG ADMINISTRATION (ed.). Bacteriological Analytical Manual. Silver Spring: FDA, 2010.

4 Transcrição de entrevista semiestruturada com o produtor Vicente no dia 02 de agosto de 2018. 
BRASIL. Ministério da Agricultura e do Abastecimento. Instrução Normativa ${ }^{\circ} 30$, de 26 de junho de 2000. Regulamento Técnico de Identidade e Qualidade de Manteiga da Terra ou Manteiga de Garrafa, Queijo de Coalho e Queijo de Manteiga. Diário Oficial da República Federativa do Brasil: seção 1, Brasília, DF, n. 136, p. 13, 16 jul. 2001.

BRASIL. Ministério da Agricultura, do Abastecimento e da Reforma Agrária. Portaria $n^{\circ} 146$, de 7 de março de 1996. Aprova os Regulamentos Técnicos de Identidade e Qualidade dos Produtos Lácteos. Diário Oficial da República Federativa do Brasil: seção 1, Brasília, DF, n. 48, p. 3977, 11 mar. 1996.

CAVAlCANTE, A. B. D.; COSTA, J. M.C. Padronização da tecnologia de fabricação do queijo manteiga. Revista Ciência Agronômica, v. 36, n. 2, p. 215-220, 2005.

DOWNES, F. P.; ITO, K. (ed.). Compendium of methods for the microbiological examination of foods. 4th ed. Washington: American Public Health Association - APHA, 2001.

FERREIRA, D. F. SISVAR: A computer statistical analysis system. Ciência e Agrotecnologia, v. 35, n. 6, p. 1039-1042, 2011. DOI: $10.1590 / \mathrm{S} 1413-70542011000600001$.

HORWITZ, W. (ed.). Official methods of analysis of AOAC International. 17th ed. Gaithersburg: AOAC International, 2000.

JASSEN-ESCUDERO, C.; RODRIGUEZAMÁYA, D. B. Composition of the Brazilian cheese requeijão do norte. Journal of Food Science, v. 46, n. 3, p. 917-919. 1981. DOI: /10.1111/j.1365-2621.1981.tb15380.x
NASSU, R. T. et al. Diagnóstico das condições de processamento e caracterização físicoquímica de queijos regionais e Manteiga no Rio Grande do Norte. Boletim de Pesquisa e Desenvolvimento, n. 11. Fortaleza: Embrapa Agroindústria Tropical, 2003. 24 p.

OLIVEIRA, C. S. Queijos Artificiais. Revista do Instituto de Laticínios Cândido Tostes, v. 39, n. 235, p. 49-51. 1984.

PINTO, F. G. S. et al. Qualidade microbiológica de queijo Minas frescal comercializado no município de Santa Helena, PR, Brasil. Arquivos do Instituto de Biologia, v.78, n.2, p. 191-198, 2011.

SANTOS, J. S. et al. Diagnóstico das condições de processamento de produtos artesanais derivados do leite no estado de Sergipe. Revista do Instituto de Laticínios Cândido Tostes, v. 63, n. 363, p. 17-25. 2008.

SEIXAS, V. N. C. et al. Caracterização do queijo do Marajó tipo manteiga produzido em duas estações do ano. Revista Ciência Rural, v. 45, n. 4, p. 730-736, 2014. DOI: $10.1590 / 0103-8478$ cr20140463

ZAFFARI, C. B.; JOZI, F. M. COSTA, M. Qualidade bacteriológica de queijos artesanais comercializados em estradas do litoral norte do Rio Grande do Sul, Brasil. Revista Ciência Rural, v. 37, n. 3, p. 862-867, 2007. DOI: 10.1590/S0103-84782007000300040

ZENEBON, O.; PASCUET, N. S.; TIGLEA, P. (coord.). Métodos Físico-Químicos para Análise de Alimentos. 4. ed., 1. ed. digital. São Paulo: Instituto Adolfo Lutz, 2008.1020 p. 